\title{
Should General Practice be a Speciality in its own right?
}

Richard J McManus MA, PhD, FRCGP, FRCP (Professor) \& FD Richard Hobbs MA, FRCGP, FRCP (London), FESC, FMedSci, FRCP (Edin) (Professor)

Nuffield Department of Primary Care Health Sciences

University of Oxford

Radcliffe Observatory Quarter

Woodstock Road

Oxford

OX2 6GG

$\mathrm{T}:+44(0) 1865617834$

F: $+44(0) 1865289287$

Corresponding Author: richard.mcmanus@phc.ox.ac.uk

826 words plus references 
General Practice as known today in the UK, developed in the nineteenth and early twentieth centuries as it became distinct from medical activities centred on hospitals. ${ }^{1}$ General Practitioners (GPs) became gradually separated from physicians and surgeons and took on the role of a personal doctor working in the community. This generalist role was differentiated from "specialists" who consulted patients referred to them from GPs. However, the respective roles of GPs and hospital specialists have become blurred, especially since the 1990s, with GPs taking on much of the traditional hospital care in the diagnosis and management of major diseases (diabetes, hypertension, thyroid disease, mental health); most preventive medicine (cancer screening, immunisation, maternity); and even 'surgical' procedures, (IUD insertions, joint injections, and lesion removal). This has resulted in the disappearance of the general physician role with hospitals and greater superspecialisation of consultants. What has not transferred has been the 'specialist' label for the doctors now delivering this prior hospital care.

Last month saw a joint statement from the BMA and RCGP supporting a call by the European Union of General Practitioners for General Practice to be recognized as a specialty in its own right. ${ }^{2}$ Most European States along with Australia, and North America already recognise GPs or Family Physicians as specialists so what would be the consequence of such a change here?

The ability to practice in the UK requires registration by the General Medical Council (GMC) which provides separate registers for GPs and specialists. ${ }^{3}$ At the most basic level, entry onto the specialist register requires a certificate of completion of training - but so does entry onto the GP register. Such training is described by the GMC as "specialist training" for both GPs and consultants. Both types of training programmes are rigorous and require exit examinations and membership of a respective Royal College. General Practice training is shorter (5/6 years post qualification) compared to many other specialities but other than that the criteria for specialist and generalist status seem very similar. Whilst combining GP and specialist registers into a single register would require new legislation, would it result in any more than a change in nomenclature and would it be worth it?

The main motivation behind calling for such a change centres around the status of GPs: that the differentiation is "anachronistic anomaly" and that the status of general practitioners should be "equal" to that of their secondary care colleagues. ${ }^{2}$ It is hard to imagine that a 
simple change in registration would result in such equality and some GPs have expressed the view at such changes in labelling are very low priority compared to the difficulties facing the profession in 2016. However, perhaps now is the time to do everything possible that might improve recruitment and retention into general practice, and the perceived lower status of general practice is an enduring barrier everywhere,${ }^{4}$ alongside fairer pay and the control of burgeoning workloads - GPs in the UK have seen dramatic reductions in income and a $16 \%$ increase in clinical workload in the past few years, ${ }^{5}$ leading to the lowest job satisfaction ratings since surveys were started. ${ }^{6}$

GPs are by nature and name generalists. We deal with whatever presents to us whether physical, psychological, spiritual or most commonly a combination of all three and more. There is a certain tautology in labelling a generalist as a specialist and many pride themselves on their abilities as the former. Nevertheless, GPs are without doubt specialists in general medicine. They are the only medical speciality to look after individuals from cradle to grave and whilst patients may move between practices (along with their records), it is not unusual to hear of links to the practice of fifty years or more. Such relationships are unique and lead to a particular kind of medicine practiced in small instalments over many years.

What possible consequences could a change to specialist result in? Could there be unintended consequences as we move into the brave new work of the General Practice Forward view. GPs already work with nursing, administrative, pharmacy, midwifery and other staff. Physicians associates - already familiar in North America - are set to become more common in the UK and they may influence the unique generalist role hitherto maintained by GPs. ${ }^{7}$ Working within new organisational structures including so called "multi-speciality providers" and extended partnerships alongside consultant colleagues will inevitably change the place of the GP, specialist or not. Whether such changes are for the better remains to be seen. Alongside these major structural changes, re-badging general practice as a medical speciality would appear opportune. Indeed, given the greater differentiation of GP roles, with GPs with specialist interests, with far more salaried GPs and far fewer partners, perhaps the time has come to differentiate the role more in line with hospital doctors and establish consultants in primary care (or general practice)? Whether 
for all GPs or a proportion, this could send a powerful message of confidence by the NHS at a time the service is under extreme stress.

\section{Licence}

The Corresponding Author has the right to grant on behalf of all authors and does grant on behalf of all authors, a worldwide licence

(http://www.bmj.com/sites/default/files/BMJ\%20Author\%20Licence\%20March\%202013.do

c) to the Publishers and its licensees in perpetuity, in all forms, formats and media (whether known now or created in the future), to i) publish, reproduce, distribute, display and store the Contribution, ii) translate the Contribution into other languages, create adaptations, reprints, include within collections and create summaries, extracts and/or, abstracts of the Contribution and convert or allow conversion into any format including without limitation audio, iii) create any other derivative work(s) based in whole or part on the on the Contribution, iv) to exploit all subsidiary rights to exploit all subsidiary rights that currently exist or as may exist in the future in the Contribution, v) the inclusion of electronic links from the Contribution to third party material where-ever it may be located; and, vi) licence any third party to do any or all of the above.

\section{Contributorship:}

$\mathrm{RM}$ and FDRH jointly wrote this editorial and agreed the final version.

\section{Competing Interests:}

We I/we have read and understood the BMJ Group policy on declaration of interests and declare the following interests: RM and FDRH are both practicing part time General Practitioners. RM holds shares in a company which provides General Medical Services. 


\section{References}

${ }^{1}$ Ian Tait. A History of the College. RCGP London 2002. http://www.rcgp.org.uk/aboutus/history-heritage-and-archive/history-of-the-college.aspx Accessed 11/9/2016

2 Joint BMA/RCGP Statement on General Practice as a Speciality: http://www.rcgp.org.uk/news/2016/august/ /media/Files/News/2016/Joint-BMA-RCGPstatement-August-2016\%20(1).ashx Accessed 15/9/2016.

${ }^{3}$ General Medical Council Register: http://www.gmc-uk.org/doctors/register/LRMP.asp Accessed 15/9/2016

${ }^{4}$ Smith SR: A recipe for medical schools to produce primary care physicians. N Engl J Med 2011, 364(6):496-497

${ }^{5}$ Hobbs FDR, Bankhead C, Mukhtar T, Stevens S, Perera-Salazar R, Holt T, Salisbury C; National Institute for Health Research School for Primary Care Research. Clinical workload in UK primary care: a retrospective analysis of 100 million consultations in England, 2007-14. Lancet. 2016 Apr 5. pii: S0140-6736(16)00620-6. doi: 10.1016/S0140-6736(16)00620-6.

${ }^{6}$ Gibson J, Checkland K, Coleman A, Hann M, McCall R, Spooner S, Sutton M. Eighth National GP Worklife Survey Report. Available from http://www.populationhealth.manchester.ac.uk/healtheconomics/research/Reports/EighthNationalGPWorklifeSur veyreport.pdf accessed 15/9/2016.

7 Primary Care Workforce Commission: http://hee.nhs.uk/work-programmes/primary-andcommunity-care-programme/primary-care-workforce-commission/ Accessed 15/9/2016 